\title{
ANALISE DE INCERTEZAS EM SISTEMAS PETROLÍFEROS
}

\section{SIDNEI PIRES ROSTIROLLA}

\begin{abstract}
UNCERTAINLY ANALYSIS IN OIL-BEARING SYSTEMS This paper discusses a model to evaluate uncertainties and success probabilities in petroleum exploration. In the model, assessment of undiscovered oil and gas potential can be made in a probability format, which is based on petroleum system analyses. The evaluated area is mapped in order to define the essential elements of petroleum systems, when the probabilities of occurrence of diagnostic factors are calculated using the presence and absence of guides in productive and dry areas. The study implies, organization of petroleum system oriented databases and statistical analysis of their component data sets. For the estimation of uncertainties a method of updating probabilities is presented in two steps: 1) description and modeling of potential petroleum systems in the evaluated area, based on the essential elements (generation, reservoir, charge, retention and efficiency) and 2) categorization of selected data in control-areas to calculate the necessity and sufficiency conditions of each variable, expressed as probabilities, according to the frequency of occurrence of diagnostic criteria in positive and negative drilled areas.
\end{abstract}

Keywords:

RESUMO Neste trabalho é discutido um modelo de avaliação de incertezas e probabilidades de sucesso na exploração de petróleo. No modelo, a avaliação do potencial de óleo e gás não descoberto é representada em um quadro probabilístico, baseado na análise de sistemas petrolíferos. A região avaliada é mapeada para definir os elementos essenciais de sistemas petrolíferos, quando as probabilidades de sucesso dos fatores diagnósticos de acumulações são calculadas a partir da ocorrência de guias prospectivos em áreas já testadas, produtoras e não produtoras. O estudo implica na organização de um banco de dados orientado aos modelos de sistemas petrolíferos e na análise estatística de seus dados componentes. Para a estimativa de incertezas é apresentado um método de atualização de probabilidades em duas etapas: 1) descrição e modelagem dos sistemas petrolíferos na área avaliada e de seus elementos essenciais (geração, reservatório, alimentação, retenção e eficiência) e 2) categorização dos guias prospectivos selecionados e cálculo das condições de necessidade e suficiência de cada variável, expressas como probabilidades, de acordo com a presença ou ausência da mesma em áreas de controle.

Palavras-chaves:

INTRODUÇÃo O sucesso na exploração de petróleo pode ser diferenciado segundo dois aspectos: o geológico (ou técnico) e o econômico (ou comercial). O primeiro é alcançado com a descoberta de um alvo suficientemente atrativo para justificar o custo de continuar com as atividades de prospecção e testar o seu potencial econômico. $\mathrm{O}$ segundo é obtido quando este mesmo teste prova que uma acumulação contém todos os requisitos necessários para uma operação lucrativa, considerando-se fatores geológicos, sócio-políticos, geográficos e operacionais. O sucesso geológico depende da formulação dos modelos de acumulação e da definição das incertezas sobre a ocorrência dos fatores diagnósticos geração, reservatório, alimentação, retenção e eficiência (timing) de acumulações. A questão chave é estruturar as decisões exploratórias de tal modo que a maioria dos erros fique nas etapas de prospecção regional e de semi-detalhe, sem evoluir para a fase de prospecção local, que envolve um investimento relativamente mais alto.

O termo incerteza designa a faixa de valores, em representação probabilística, que uma variável pode obter. Corresponde ao erro de uma estimativa. Um exemplo prático e simples é considerar a incerteza como o desvio padrão ao redor da média (que pode ser normalizado pelo número de dados), ou seja, uma medida da dispersão quando se faz uma estimativa. Obviamente, esta é uma definição incompleta pois não considera os erros na amostragem ou mesmo a formulação ambígua de plays e sistemas petrolíferos. Conceitualmente, a incerteza pode ser medida através do valor-verdade da afirmação sobre a ocorrência de um evento. Fazendo um paralelo com a teoria dos conjuntos difusos (fuzzy sets; e.g. Kosko 1992), quando se estima a ocorrência ou não de um evento (bivalência 1 ou 0 ), a afirmação $\mathrm{A}$ e sua negação não $\mathrm{A}$ têm o mesmo valor-verdade $\mathrm{v}(\mathrm{A})=\mathrm{v}($ não $\mathrm{A})$. Considerando que a negativa contraria o valor verdade $\mathrm{v}($ não-A $)=1-\mathrm{v}(\mathrm{A})$, a igualdade se reduz a $v(A)=1-v(A)$. Sendo A verdadeiro ou falso, ou seja se $v(A)$ $=1$ ou $\mathrm{v}(\mathrm{A})=\mathrm{O}$, pode implicar na contradição $1=0$. Por outro lado, ao invés de insistir que $\mathrm{v}(\mathrm{A})=1 \mathrm{ou} \mathrm{v}(\mathrm{A})=\mathrm{O}$, pode-se aceitar a relação lógica $\mathrm{v}(\mathrm{A})=1-\mathrm{v}(\mathrm{A})$ e simplesmente resolver-se a equação: $2 \mathrm{v}(\mathrm{A})=$ 1 , o que implica em $v(A)=1 / 2$. Assim, as afirmações são reduzidas a meias-verdades, que representam o extremo da incerteza inerente a qualquer afirmação empírica, como também a muitas observações matemáticas.

Utilizando outro exemplo, formula-se a seguinte questão sobre a presença da camada selante em um prospecto: seja um determinado valor-verdade sobre a ocorrência do selo, até que espessura e continuidade lateral o mesmo continuará sendo um selo efetivo? A litologia ainda será selante, caso a estimativa de espessura for diminuída em um metro? E se for diminuída em dois metros? E três metros? Caso seja utilizado um argumento por indução, eventualmente será diminuída toda a espessura e manter-se-á a conclusão que um selo ainda existe, ou então que ele simplesmente desapareceu. O que se percebe é que ocorre uma transição gradual de uma situação para seu oposto. Fisicamente, isto significa graus de ocorrência ou graus de verdade.
O termo risco refere-se à possibilidade de perda em um empreendimento comercial, sendo proporcional ao prejuízo econômico possível. $\mathrm{Na}$ exploração de petróleo, o risco surge quando as decisões deixam de ser baseadas somente em informações geocientíficas, para serem fundamentadas nas possibilidades do retorno financeiro decorrente da descoberta e no custo das atividades exploratórias, necessárias para que se alcance o sucesso econômico. $\mathrm{O}$ risco de um projeto exploratório deve ser estimado pela análise das conseqüências econômicas do empreendimento (Rose 1993), e medido pelo valor esperado: $\mathrm{VE}=\left(\mathrm{P}_{\mathrm{s}} \cdot \mathrm{V}_{\mathrm{r}}\right)-\left(\mathrm{Pf} . \mathrm{V}_{\mathrm{a}}\right)$, onde $\mathrm{P}_{\mathrm{s}}$ e $\mathrm{P}_{\mathrm{f}}$ são as probabilidades de sucesso e fracasso e $\mathrm{V}_{\mathrm{r}}$ e $\mathrm{V}_{\mathrm{a}}$ são os valores líquidos do retorno e da aplicação financeira do investimento, respectivamente. $\mathrm{O}$ valor do risco é calculado pela razão $R=V_{a} / V E$, com $R>1$ eqüivalendo a uma perda certa. Por exemplo, se a probabilidade de sucesso de um determinado prospecto é $\mathrm{P}_{\mathrm{s}}=0,20$, o valor presente líquido das reservas recuperáveis é $\mathrm{V}_{\mathrm{r}}=\$ 20$ milhões e o custo do empreendimento é $\mathrm{V}_{\mathrm{a}}=\$ 2$ milhões, tem-se valor esperado $\mathrm{VE}=(0,20 . \$ 20)-(0,80 . \$ 2)=\$ 2,4$ milhões e risco $\mathrm{R}=2 / 2,4=0,83$. A combinação da análise de incertezas com a análise de risco resulta na avaliação completa, efetuada com o propósito de dar suporte às decisões da companhia e criar uma vantagem competitiva. No exemplo acima, fica clara a importância que a incerteza tem para a fase subsequente de análise de risco. Com uma probabilidade de sucesso de $15 \%$, o valor esperado seria de 1,3 milhões, o que implicaria em $\mathrm{R}=1,54$, correspondendo a uma perda certa, com $\mathrm{V}_{\mathrm{a}}>\mathrm{VE \hat {E }}$. Neste caso, uma probabilidade de sucesso de $15 \%$ inviabilizaria o projeto exploratório.

Neste trabalho, é apresentado um modelo de análise das probabilidades de sucesso geológico (ou incertezas, no jargão da indústria do petróleo) em conjunto com o modelo de sistema petrolífero. Procurouse desenvolver o método com base em duas linhas: (1) qualitativa, onde as informações exploratórias são interpretadas segundo a experiência adquirida e (2) quantitativa, apoiada em dados geológicos, geoquímicos e geofísicos selecionados para possibilitar a análise de probabilidades. Diante do objetivo estabelecido, de desenvolver um trabalho de cunho metodológico, o texto foi subdividido em três partes: a. discussão sobre sistemas petrolíferos, b. apresentação dos métodos para análise de probabilidades de sucesso e c. aplicação da metodologia em uma área fictícia.

SISTEMAS PETROLÍFEROS Para a avaliação do potencial petrolífero analisa-se a presença de rocha geradora, qual é o caminho de migração, a existência de reservatório e estrutura para aprisionamento, o volume in-place, entre outros fatores. Obviamente, a presença destas condições é fundamental para que o sistema petrolífero reuna as condições para produzir uma acumulação comercial. No entanto, é importante caracterizar o valor a partir do qual as variáveis mapeadas estão realmente associadas ao processo acumulador e, consequentemente, em que grau elas são indicativas da existência de novas descobertas. A incerteza sobre a ocorrência de uma nova descoberta é 
uma função inversamente proporcional ao acerto na predição destas variáveis, ao desenvolvimento do modelo de sistema petrolífero e ao armazenamento das informações obtidas nos testes de outros prospectos. Este raciocínio considera que somente sob valores discriminados por cutoffs específicos, as variáveis podem ser consideradas como indicativas da acumulação.

As variáveis contínuas são aquelas com distribuição espacial em uma ampla faixa de valores numéricos, como por exemplo uma superfície de contorno em cotas, mapas geofísicos, mapas de isópacas, etc. As variáveis discretas exprimem objetos distintos, que podem ser distribuídos em classes (presença ou ausência), como por exemplo a existência de falhas, anomalias gravimétricas, anomalias de impedância, fácies ou atributos sedimentológicos, etc. Em programas exploratórios, as variáveis contínuas são intuitivamente analisadas como variáveis discretas, já que interessa saber se o valor encontrado pode ser classificado dentro de um código binário, que registra interesse positivo ou negativo, dependendo respectivamente da evidência favorável ou não ao processo acumulador. Não basta saber, por exemplo, se existe rocha geradora, é necessário registrar os valores que representam o potencial gerador para o modelo considerado.

Os elementos essenciais de sistemas petrolíferos (geradora, reservatório, selo e sobrecarga, conforme o modelo de Magoon \& Dow (1994) podem ser reunidos em subsistemas de alimentação, migração e trapeamento (modelo de Demaison \& Huizinga 1991 1994). Estes, por sua vez integram diversas variáveis contínuas ou discretas. Para cada uma dessas variáveis, é definida uma função (vi) que implica em uma variável indicativa, derivada do conjunto representado pela variável contínua ou discreta mapeada (v), e classificada dentro de valores diagnósticos do processo acumulador (cd - classe ou critério diagnóstico): vi(v) $=1$, se $\mathrm{v} \in \mathrm{e} \mathrm{cd}$; ou $\mathrm{vi}(\mathrm{v})=\mathrm{O}$, se $\mathrm{v} \notin \mathrm{cd}$. A análise

de incertezas consiste no entendimento das leis de associação espacial entre tais variáveis e as acumulações (coexistência e distribuição em área), para definição das probabilidades de sucesso. A seleção das variáveis de interesse, a partir de modelos de sistemas petrolíferos preestabelecidos, constitui a etapa crítica, pois representa as condições de contorno e o domínio de dados utilizados durante a análise estatística posterior.

Nas últimas duas décadas, a aplicação das técnicas exploratórias evoluiu para um sistema integrado de modelagem, que utiliza inferências científicas e associa o processamento de dados com o gerenciamento de modelos. Tais sistemas de inferências fundamentam-se no paradigma diálogo-dados-modelos (Fig. I). As informações são armazenadas, processadas e analisadas segundo uma rede de informações interativa e dinâmica, constituindo uma forma eficiente de integrar o conhecimento exploratório.

Os sistemas petrolíferos podem ser entendidos como sistemas de inferências que utilizam técnicas indutivas de análise de bacias e modelagem de acumulações, representadas por uma tecnologia de prospecção voltada à descoberta. São, portanto, sistemas do tipo diálogo-dados-modelos com conotação exploratória. Além disso, embora a sua estrutura operacional seja basicamente tecnológica, são calcados nos conceitos científicos de sistemas naturais. Um sistema natural é um conjunto estruturado de objetos e/ou atributos, que consistem de componentes ou variáveis que operam conjuntamente de acordo com algum padrão observado (Chorley \& Kennedy 1971; in Hugget 1985). Nessa concepção, o sistema petrolífero é um sistema natural, componente do macroambiente bacia sedimentar. A bacia

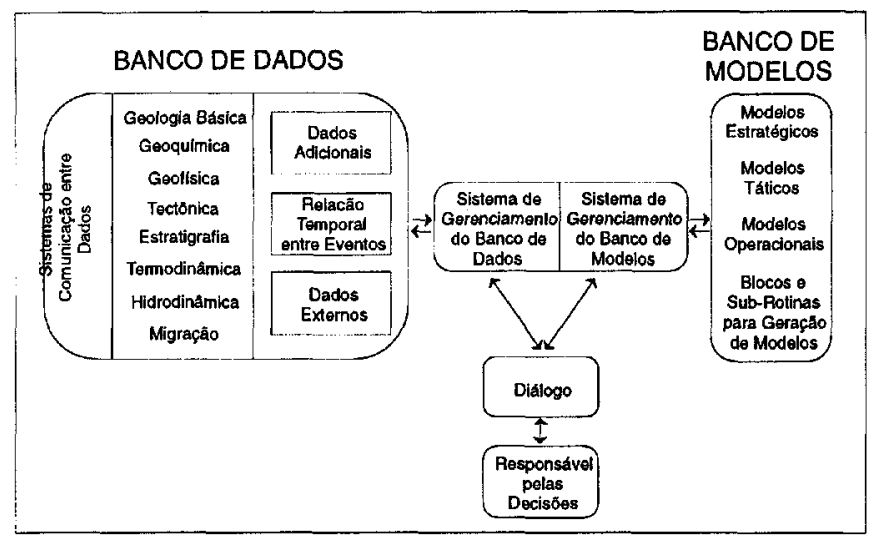

Figura l-Sistema diálogo-dados-modelos adaptado à exploração de petróleo (mod. Watson \& Sprague 1991). sedimentar é uma entidade sistêmica litosférica e o SP é uma entidade sistêmica particular onde interagem os eventos concentradores que supostamente convergiram para a formação de uma acumulação comercial. Para produzir a acumulação, um sistema petrolífero requer a convergência temporal de certos eventos e elementos geológicos essenciais. Conforme Magoon (1988; apud Magoon \& Dow 1994), a investigação apoia-se na correlação rocha-óleo, fazendo uso de análises geoquímicas, da estratigrafía e da análise estrutural dos elementos e processos geológicos essenciais. Já Demaison \& Huizinga $(1991,1994)$ definem um sistema petrolífero como um sistema físicoquímico gerador e concentrador de petróleo, funcionando numa determinada escala de espaço e tempo geológicos, sendo composto pelos subsistemas gerador e de migração-trapeamento.

Geração A ausência de geração configura uma condição restritiva ao funcionamento do sistema petrolífero. Por outro lado, uma rocha que contém matéria orgânica não representa necessariamente uma variável indicativa do fator geração. Para que assim seja, a mesma deve reunir condições adequadas de geração, para o modelo de sistema petrolífero considerado. Nessa linha de raciocínio, Peters \& Cassa (1994) caracterizam uma rocha geradora efetiva como aquela que cumpre três requisitos: quantidade de matéria orgânica, qualidade da matéria orgânica e maturidade (Tabs, 1, 2 e 3).

A expulsão de hidrocarbonetos da rocha geradora ocorre quando a saturação em folhelhos (fração da microporosidade ocupada por hidrocarbonetos) excede $10-20 \%$ (Fig. 2). Normalmente, a eficiência de expulsão aumenta com o aumento da maturidade, alcançando 80 a $90 \%$ para rochas ricas e maturas. Nessa fase do processo a sobrepressão promove expulsão por fraturamento hidráulico.

Os principais critérios utilizados para caracterizar seletivamente as variáveis indicativas de geração são baseados principalmente em: 1) teor de carbono orgânico total - COT - ou medida relativa do carbono presente na forma de querogênio e betúmen e 2) pirólise da rocha pirólise rock-eval - processo desenvolvido por Espitalié (1977; in Allen \& Allen 1990), onde o pico S1 representa o hidrocarboneto que já estava na rocha antes da pirólise, o pico S2 o hidrocarboneto produzido em altas temperaturas pela quebra do querogênio e o pico $\mathrm{S} 3$ os componentes voláteis, $\mathrm{CO}_{2}$ e $\mathrm{H}_{2} \mathrm{O}$.

Tabela l-Parâmetros geoquímicos utilizados para estimar a quantidade de matéria orgânica existente em uma rocha geradora imatura (mod. Peters \& Cassa 1994)

\begin{tabular}{|c|c|c|c|c|c|c|}
\hline \multirow[b]{2}{*}{ Potencial } & \multicolumn{2}{|c|}{ Matéria Orgânica } & \multicolumn{2}{|c|}{ Betúmen } & \multicolumn{2}{|c|}{$\mathrm{HC}$} \\
\hline & $\cot (\%)$ & $\begin{array}{c}\text { S1 } \\
(\mathrm{mmHC} / \mathrm{K})\end{array}$ & $\begin{array}{c}\mathrm{S2} \\
(\mathrm{mmHC} / \mathrm{k} g)\end{array}$ & (\%) & (ppm) & $(\mathrm{ppm})$ \\
\hline Pobre & $0-0,5$ & $0-0,5$ & $0-2,5$ & $0-0,05$ & $0-500$ & $0-300$ \\
\hline Razóável & $0,5-1$ & $0,5-1$ & $2,5-5$ & $0,05-0,10$ & $500-1000$ & $300-600$ \\
\hline Bom & $1-2$ & $1-2$ & $5-10$ & $0,10-0,20$ & $1000-2000$ & $600-1200$ \\
\hline Muito Bom & $2-4$ & $2-4$ & $10-20$ & $0,20-0,40$ & $2000-4000$ & $1200-2400$ \\
\hline Excelente & $>4$ & $>4$ & $>20$ & $>0,40$ & $>4000$ & $>2400$ \\
\hline
\end{tabular}
$\mathrm{S} 2$ - mmHC/Kg gerado a partir da quebra do qucrogênio por pirólise: Betúmen - fração da matéria orgânica que pode ser dissolvida por solventes orgânicos; HC - Hidrocarbonctos)

Tabela 2 - Parâmetros geoquímicos utilizados para estimar o tipo de matéria orgânica e a característica do produto expelido (mod. Peters \& Cassa 1994)

\begin{tabular}{|l|l|l|l|l|}
\hline $\begin{array}{c}\text { Tipo de } \\
\text { Querogênio }\end{array}$ & \multicolumn{1}{|c|}{ IH } & \multicolumn{1}{|c|}{ S2/S3 } & \multicolumn{1}{|c|}{ H/C } & $\begin{array}{c}\text { Produto expelido no pico } \\
\text { de maturidade }\end{array}$ \\
\hline I & $>600$ & $>15$ & $>1,5$ & Oleo \\
\hline II & $300-600$ & $10-15$ & $1,2-1,5$ & Oleo \\
\hline II/ III & $200-300$ & $5-10$ & $1,0-1,2$ & Misto óleo e Gás \\
\hline III & $50-200$ & $1-5$ & $0,7-1,0$ & Gás \\
\hline IV & $<50$ & $<1$ & $<0,7$ & Nenhum \\
\hline
\end{tabular}

(Querogênio - fração da matéria orgânica insolúvel em solventes orgânicos; IH - índice de Hidrogênio; S2/S3 - razão entre os picos S2 e S3, gerados a partir da quebra do querogênio por pirólise; H/C - Razão atômica entre hidrogênio e carbono)

Tabela 3 - Parâmetros geoquímicos utilizados para estimar o nivel de maturação (mod. Peters \& Cassa 1994)

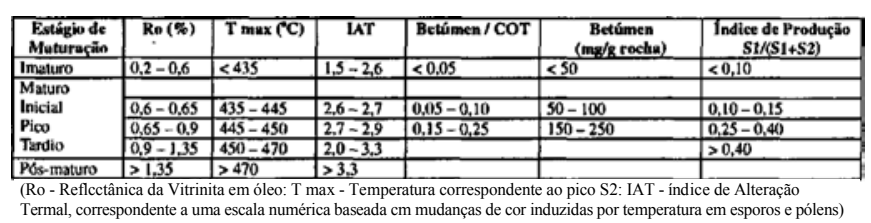


Demaison \& Huizinga (1994) ainda sugerem a utilização do índice de potencial gerador (Source Potential Index - SPI), que inclui, além da quantidade e qualidade da matéria orgânica, a capacidade volumétrica da rocha geradora (extensão lateral e espessura): $\mathrm{SPI}=[\mathrm{h}(\mathrm{S} 1+\mathrm{S} 2) \mathrm{d}] / 1000$, onde d é a densidade e h é a espessura da rocha geradora. Com base no SPI, diferentes sistemas petrolíferos podem ser hierarquizados (com potencial genético $\mathrm{S} 1+\mathrm{S} 2$ alto) que pode ser gerado em uma coluna de rocha sob uma área superficial de $1 \mathrm{~m}$. Dessa maneira, são utilizados limites numéricos para categorizar as variáveis indicativas de geração, para sistemas drenados lateralmente (SPI $<2$ - baixo; $2 \leq \mathrm{SPI}<7$ - moderado e $\mathrm{SPI} \geq 7$ - alto) ou drenados verticalmente $(\mathrm{SPI}<5$ - baixo; $5 \leq \mathrm{SPI}<15$ - moderado e $\mathrm{SPI} \geq 15$ alto).

Com os parâmetros geoquímicos devidamente estimados (seja $\mathrm{COT}, \mathrm{S} 1+\mathrm{S} 2$, SPI, ppm HC, etc.) podem ser caracterizadas as condições de necessidade e suficiência das rochas potencialmente geradoras. Para isto basta analisar as faixas de valores típicas de bacias produtoras análogas e confrontar com os valores- medidos para o prospecto.

Alimentação O petróleo é gerado a partir da quebra das moléculas de querogênio na rocha geradora, causada pelo aumento da temperatura atuante em determinado tempo. Altas temperaturas (idealmente entre 100 a $150{ }^{\circ} \mathrm{C}$ para óleo, ou até $180^{\circ} \mathrm{C}$ para gás) induzem a maturação e a expulsão de petróleo, que depois sofre movimentação ascendente por flutuabilidade, quando em condições hidrostáticas, ou por flutuação associada ao fluxo de fluidos em condições hidrodinâmicas. Segundo Ungerer et al. (1990), quando a saturação em óleo residual alcança 0,5 a $4 \%$, as forças de flutuação e a pressão interna condicionam a movimentação de hidrocarbonetos. A saturação é sempre maior no topo do que na base da camada e depende do ângulo de mergulho, viscosidade, taxa de suprimento de hidrocarbonetos e permeabilidade. A movimentação pode ser representada por direções ortogonais às isolinhas de contorno da camada impermeável que controla a migração (Fig. 3).

A migração também ocorre ao longo de falhas (Weber \& Mandl 1978), com o movimento do petróleo ocorrendo quando a pressão de fluidos excede a pressão capilar, restritiva ao fluxo. Em épocas de atividade, as falhas comportam-se como conduto, instalando-se um gradiente de pressão derivado de diferentes colunas hidrostáticas. A tendência de ocorrer migração através de falhas é menor do que ao longo de camadas, porque a permeabilidade tectônica é menos eficaz do que a permeabilidade sedimentar. Entretanto em situações específicas a migração em falhas pode ser mais efetiva em função do maior gradiente de pressão apresentado, além da facilidade de convergência de fluxo. Conforme o modelo de Sluijk \& Nederlof (1984), a área de drenagem é representada pela região que contém a rocha fonte e está abaixo do topo da zona matura, ao longo da qual ocorre o fluxo ascendente de petróleo. Para que ocorra alimentação, é necessária a convergência de fluxos a partir da área de drenagem em direção a uma área de retenção (Fig. 4).

Estágio Imaturo

Saturaçăo em Óleo $\mathbf{~} 1=0 \%$

Expulsão de Água

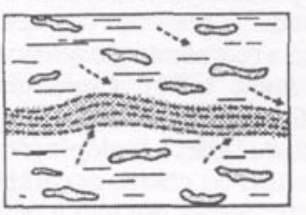

$\cdots+$ Água $\longrightarrow$ Oleo (2) Saturaçăo em Óleo $S 2=5 \%$ Hidrocarbonetos invadem a microporosidade, mas năo há expulsão

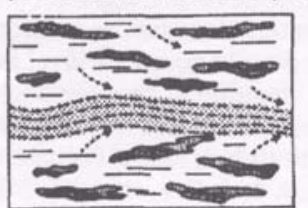

Estágio Maturo

Saturação em Óleo $\$ 3>20 \%$

Expulsảo de Óleo

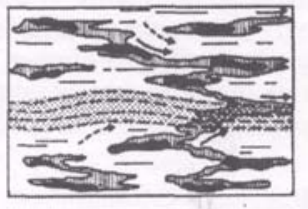

(4)

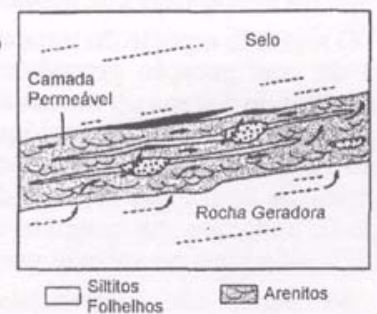

Figura 2 - l a 3 - Estágios de expulsão de água e óleo e respectivas saturações em óleo baseadas em dados de pirólise rock-eval; 4 -
A eficácia da alimentação em sistemas petrolíferos depende de três conjuntos de fatores (Demaison \& Huizinga 1994): 1) geração de petróleo em qualidade e volume adequados, ocorrendo durante ou logo após o tempo de formação da trapa; 2) geometria favorável da área de drenagem, levando ao movimento convergente de petróleo em direção à área de retenção, antes que ocorra dispersão e escape em superfície e 3) estilo e efícácia do mecanismo de migração. Com base nesses fatores, faz-se a caracterização das variáveis indicativas da alimentação (Tabela 4).

Reservatório A capacidade de uma rocha para acomodar um volume significativo de fluidos depende de atributos como profundidade, porosidade e permeabilidade, decorrentes do ambiente deposicional e da diagênese posterior. $\mathrm{O}$ ambiente deposicional fica registrado na distribuição faciológica, arquitetura e geometria dos corpos (a)

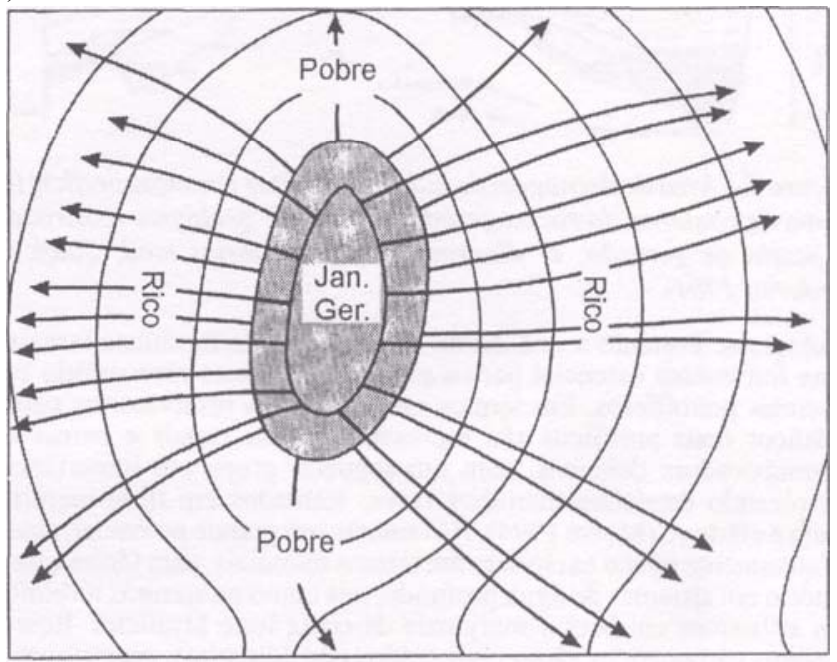

(b)

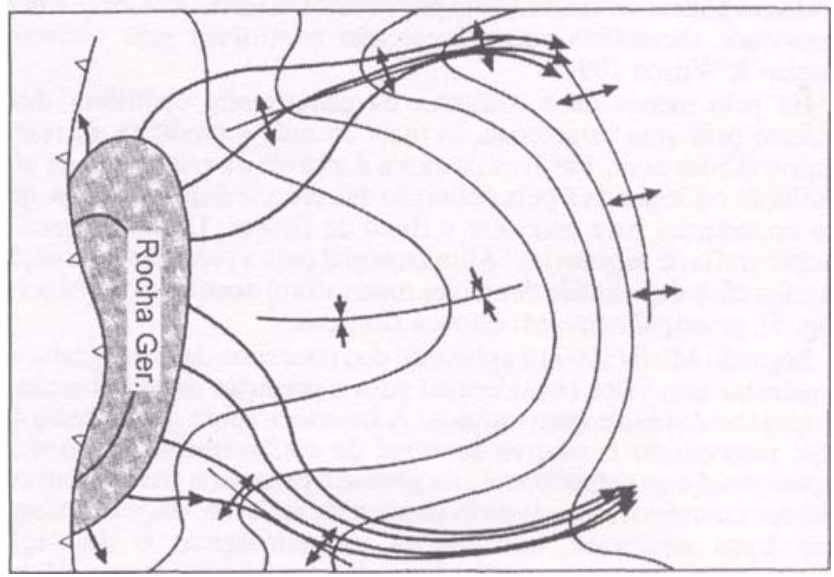

Figura 3 - Mapas com as direções de fluxo ortogonais ao contorno estrutural (mod. Allen \& Allen 1990).

Tabela 4 - Variáveis indicativas do fator alimentação.

\begin{tabular}{|l|l|}
\hline Fator & Variável Indicativa \\
\hline Potencial volumétrico & $\begin{array}{l}\text { Valor (em KgHChton) acima do qual a } \\
\text { alimentação pode ser considerada adequada }\end{array}$ \\
\hline Fluxo térmico & Medidas de Ro, Tmax e IAT (Tabela III) \\
\hline $\begin{array}{l}\text { Mecanismos de migração lateral e zonas de } \\
\text { convergência do fluxo }\end{array}$ & $\begin{array}{l}\text { Mapas de ortocontomo de camadas } \\
\text { permeáveis, discordâncias, janclas, ete }\end{array}$ \\
\hline $\begin{array}{l}\text { Mecanismos de migração vertical, } \\
\text { comparativamente ao estilo deformativo } \\
\text { atuante na época principal de migraçấo }\end{array}$ & $\begin{array}{l}\text { Correlação entre as falhas ativas no pico de } \\
\text { geração e a convergência do fluxo; Mapas } \\
\text { palinspáticos }\end{array}$ \\
\hline $\begin{array}{l}\text { Distribuiçăo das camadas geradoras dentro da } \\
\text { área de drenagem }\end{array}$ & $\begin{array}{l}\text { Correlação espacial entre as zonas com maior } \\
\text { espessura de rocha fonte e os principais canais } \\
\text { de migração }\end{array}$ \\
\hline $\begin{array}{l}\text { Entropia do sistema (ou tendência à dispersão } \\
\text { do petróleo) }\end{array}$ & $\begin{array}{l}\text { Estilo deformativo, densidade de fraturamento } \\
\text { e taxas de deformaçăo }\end{array}$ \\
\hline $\begin{array}{l}\text { Movimentação da água de formaçẵo na área } \\
\text { de drenagem (favorável ou restritiva) }\end{array}$ & $\begin{array}{l}\text { Fluxo de fluidos na bacia, gradientes de } \\
\text { pressão hidráulica }\end{array}$ \\
\hline
\end{tabular}




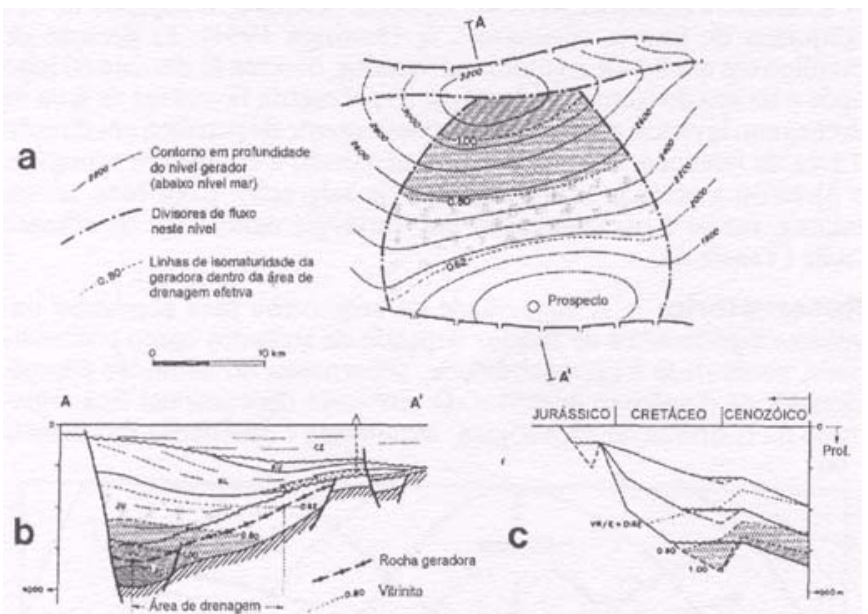

Figura 4-Área de drenagem de hidrocarbonetos em subsuperficie (a. mapa de contorno da rocha geradora; b. perfil geológico mostrando a janela de geração; c. diagrama de geohistória; mod. Sluijk \& Nederlof 1984).

litológicos. Portanto a análise de seqüências estratigráficas torna-se uma ferramenta essencial para a predição de fácies reservatório em sistemas petrolíferos. Em termos estatísticos, os reservatórios siliciclásticos mais prolíficos são representados por canais e barras de desembocadura deltaicos, com um segundo grupo em importância envolvendo depósitos marinhos rasos, formados em ilhas-barreira, praia e offshore (Morse 1994). Há também um grande potencial, ainda relativamente pouco explorado em termos mundiais, para fácies reservatório em sistemas de água profunda, tais como os arenitos turbidíticos existentes em bacias marginais da costa leste brasileira. Reservatórios carbonáticos são representados por dolomitos, grainstones e boundstones depositados principalmente em ambiente marinho plataformal. Convém lembrar, no entanto, que quaisquer litofácies carbonáticas podem ser modificadas por eventos diagenéticos, originando porosidade secundária com gênese não controlada pelo ambiente (Jordan \& Wilson 1994).

Há pelo menos duas maneiras da estratigrafia contribuir diretamente para uma caracterização mais acurada e preditiva do reservatório (Cross et al. 1993): a primeira é através da correlação de alta resolução e a segunda é pela definição das propriedades da rocha, que são importantes para controlar o fluxo de fluidos. De modo geral a "estratigrafia de seqüências" é fundamental para a predição da posição estratigráfica e qualidade das fácies reservatório dentro das seqüências (Fig. 5), principalmente em estudos sísmicos.

Segundo Miall (1997) a aplicação dos conceitos da estratigrafia de seqüências tem valor considerável para a predição da distribuicão e heterogeneidades de reservatórios. A incerteza sobre a existência do fator reservatório é relativa ao nível de conhecimento do modelo deposicional e ao entendimento da gênese e geometria das seqüências. Estudos completos, envolvendo sísmica de reflexão, poços, analogia com áreas aflorantes, informações paleontológicas e simulação numérica, implicam em resultados mais confiáveis. A experiência mostra que atributos tais como porosidade, permeabilidade e heterogeneidade representam as características determinantes (Tabela 5).

Retenção Os mecanismos de expulsão e migração, se comparados a outros processos geológicos, são pouco eficientes e, portanto, a existência de acumulações de petróleo requer a convergência da drenagem de grandes volumes para trapas volumetricamente muito menores. Além da análise do estilo de migração, é fundamental determinar se a drenagem é convergente ou divergente, sendo necessário entender o grau de resistência à dispersão do petróleo no macroambiente (entropia do sistema petrolífero). A entropia, ou fator de resistência à migração, é chamado por Demaison \& Huizinga (1991) de impedância. O grau de deformação tectônica e a integridade da rocha selante são os dois parâmetros-chave usados para qualificar os estilos de trapeamento. Os sistemas de alta impedância são caracterizados por selos lateralmente contínuos associados a um grau alto a moderado de deformação (a continuidade regional do selo é essencial para as características de integridade e retenção das trapas, em relação às áreas de drenagem ao seu redor). Sistemas de baixa impedância são caracterizados ou por selos contínuos associados à um baixo grau de

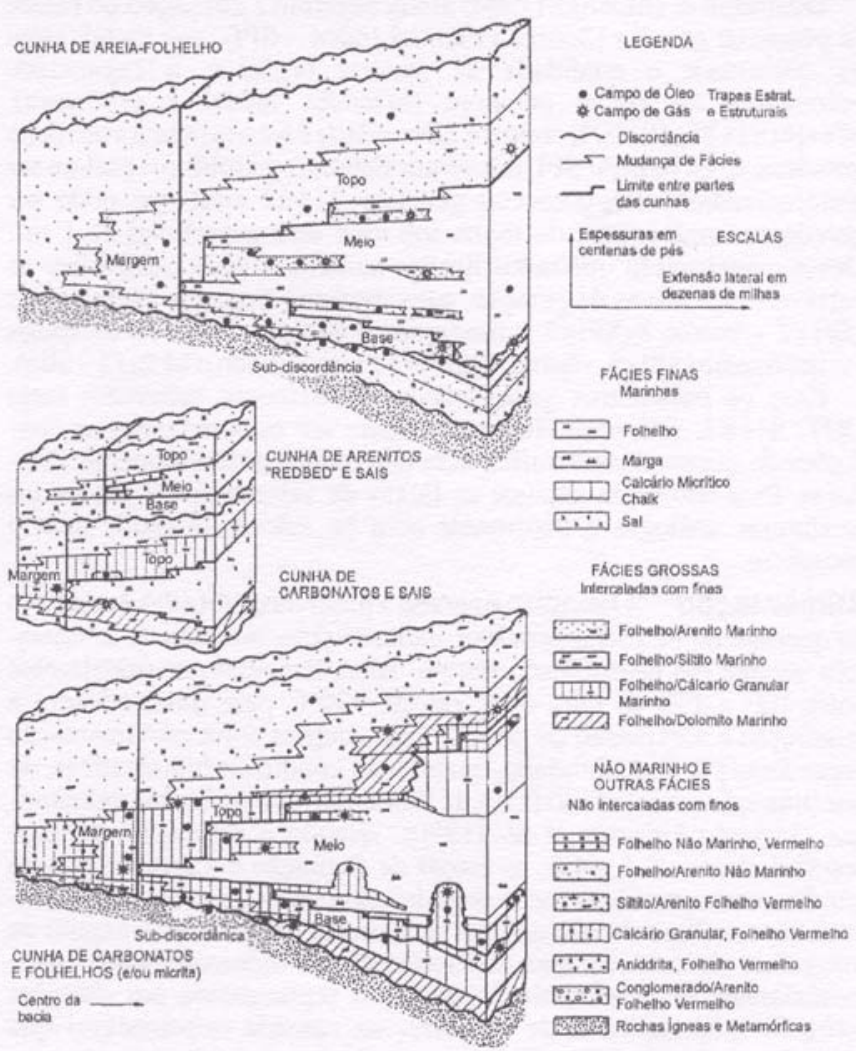

Figura 5 - Distribuição de fácies reservatório em cunhas trans gressivo-regressivas (mod. White 1980).

\section{Tabela 5 - Variáveis indicativas do fator reservatório.}

\begin{tabular}{|l|l|}
\hline Fator & Variável Indicativa \\
\hline Capacidade Volumétrica & $\begin{array}{l}\text { Curvas de porosidade, mapas de } \\
\text { isólitas, dados sísmicos 2D e 3D }\end{array}$ \\
\hline Transmissibilidade de Fluidos & $\begin{array}{l}\text { Estimativa de permeabilidade, } \\
\text { análise do ambiente deposicional, } \\
\text { razão areia-folhelho, compactação } \\
\text { e diagênese }\end{array}$ \\
\hline Heterogeneidade & $\begin{array}{l}\text { Dados sísmicos 2D e 3D, mapas } \\
\text { de litofácies, mapas de atributos e } \\
\text { isópacas }\end{array}$ \\
\hline
\end{tabular}

deformação, ou por selos regionais menos efetivos, neste segundo caso independendo do grau de deformação.

O entendimento da deposição e da integridade da rocha selante é fundamental para definirem-se locais propícios para a retenção. Nesse sentido deve-se trabalhar com mapas de isópacas da rocha selante, suas características físicas e deformação registrada. A presença (ou ausência) do selo como variável indicativa, exige a representação adequada das seguintes propriedades físicas (Downey 1994): capilaridade (pressão mínima que suporta a força de flutuação do fluido, Fig.6), continuidade lateral (geometria e arquitetura de fácies), litologia (ocorrência de halita, anidrita, folhelhos, carbonates ou chert), ductilidade (tendência da rocha fluir e responder plasticamente durante a deformação), espessura (manutenção das características deposicionais ao longo do tempo e taxa de sedimentação).

O segundo aspecto do trapeamento de hidrocarbonetos é a existência de configuração geométrica apropriada da rocha reservatório, constituindo a trapa ou armadilha para a retenção de fluidos. A trapa é portanto uma entidade geológica que integra uma rocha reservatório com forma, capacidade volumétrica adequada e um selo efetivo. O volume de óleo e gás preservado depende da predição do tamanho e tipo da trapa que, em conjunto com a migração, constitui o fator com maior influência no sucesso geológico.

As trapas são classificadas em estruturais, estratigráficas e hidrodinâmicas (Figura 7 e Tabela 6). Tal divisão é baseada na comparação entre prospectos e na análise da associação espacial entre estruturas trapeadoras e campos conhecidos. A principal subdivisão, 
baseada essencialmente nos processos formadores, é feita entre trapas estruturais, nas quais a maioria dos recursos são encontrados, e trapas estrati gráficas.

ANÁLISE DE INCERTEZAS Calibração do Modelo A análise de incertezas e probabilidades de sucesso na exploração de sistemas petrolíferos representa uma etapa importante para a seleção de alvos, com a importância de cada variável indicativa sendo estimada a partir de sua existência em áreas produtoras e não produtoras. O ponto fundamental consiste em transformar as analogias geológicas em analogias estatísticas, com o potencial sendo definido através da integração das $\mathrm{n}$ variáveis reconhecidas na mesma área-alvo. A estratégia é similar a de Otis \& Schneidermann (1997), onde a caracterização do sucesso geológico baseia-se na análise dos elementos essenciais de plays e sistemas petrolíferos.

No presente texto, a metodologia é modificada no modo de cálculo das probabilidades de sucesso, que passam a traduzir as condições de necessidade e suficiência das variáveis indicativas. Na lógica matemática, a condição de necessidade considera que a validade de uma proposição B (acumulação) somente é possível se a proposição A (variável) for válida; já a condição de suficiência significa que a validade da proposição B é satisfeita pela validade da proposição $\mathrm{A}$. Neste trabalho, uma variável é considerada necessária quando a sua ausência é restritiva à acumulação e suficiente quando a sua presença é sugestiva. Em termos estatísticos, a necessidade é um valor diretamente proporcional à probabilidade da variável indicativa (vi) não ocorrer em poços secos $[\mathrm{P}(\mathrm{vi} \mid \mathrm{A})]$, enquanto a suficiência é representada pela sua probabilidade de ocorrência em poços produtores $[\mathrm{P}(\mathrm{vi} \mid \mathrm{A})]$. Portanto, quanto maior a ausência da variável em prospectos negativos, maior a necessidade, e quanto maior a sua freqüência em prospectos positivos, maior a suficiência. $\mathrm{O}$ modelo de acumulação previsto para o prospecto deve ser idêntico ao das áreas de controle, sob pena de falsear os resultados. Caso existam diferentes plays dentro do mesmo sistema, devem ser selecionados os prospectos do mesmo tipo para calibração.

Quantificação das Probabilidades O primeiro passo consiste em definir o momento crítico do sistema petrolífero (Magoon \& Dow 1994), para depois serem categorizadas as variáveis. Para cada fator diagnóstico na área de controle (Tabela 7), são definidas as categorias das variáveis (critério presente $=1$, ou ausente $=0$ ). As variaveis representativas dentro de cada fator diagnóstico normalmente são condicionalmente dependentes entre si, já que na maioria dos casos registram o mesmo processo acumulador. Assim sendo, deve-se considerar a variável mais representativa do processo acumulador definido durante a análise do sistema petrolífero, ou então definir uma única função englobando os fatores dependentes.

A incerteza é então estimada como a medida da crença sobre a ocorrência dos fatores diagnósticos, para o mesmo modelo de acumulação. Ou seja, o banco de dados utilizado (ou domínio) é totalmente dependente do modelo de acumulação previsto, que neste caso funciona como um parâmetro para categorizacão das variáveis indicativas. Se o modelo for inadequado ou se as variáveis mapeadas não apresentarem um poder preditivo razoável, o resultado poderá ser falseado. Após o cálculo, as probabilidades de sucesso são, aqui, arbitrariamente classificadas nos intervalos: Fraca $(0,0-0,2)$, Regular $(0,2-0,4)$, Boa $(0,4-0,6)$, Muito Boa $(0,6-0,8)$, Excelente $(0,8-1,0)$.

A Tabela 8 apresenta alguns cálculos de necessidade e suficiência de fatores diagnosticos existentes em um prospecto hipotético, calibrados pelo histórico de ocorrência em outros prospectos com modelo de acumulação semelhante. São considerados 100 poços para calibração, onde 30 resultaram produtores e 70 foram secos. Partindo da premissa que as condições de necessidade e suficiência são independentes entre si e representam probabilidades condicionais, a probabilidade indicada para cada fator diagnóstico, ou probabilidade individual de sucesso (PS), é representada pela multiplicação de

$$
P(\bar{V} \mid \bar{A})=\frac{\bar{V} \cap \bar{A}}{\bar{A}}
$$

por

$$
P(V \mid A)=\frac{V \cap A}{A}
$$

Neste caso a probabilidade é subjetiva, pois depende do conhecimento prévio e do modo como o mesmo é utilizado. A escola que utiliza este conceito é chamada de escola bayesiana, também conhecida como "estatística das causas". O teorema de Bayes pode ser escrito simplesmente como urna função da probabilidade condicional de que um evento $B i$ possa ocorrer, dado que $A$ seja observado:

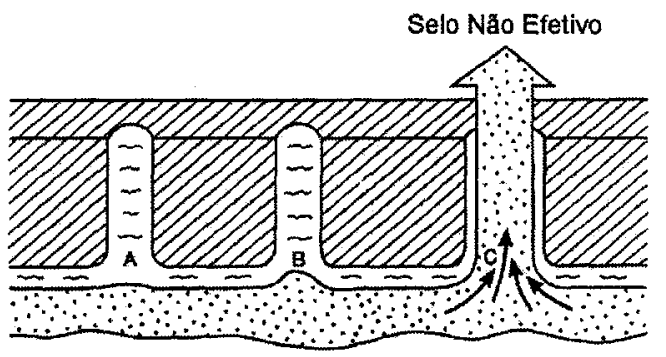

Pressão capilar excede a pressão por flutuaçăo de hidrocarboneto

c: Grandes poros têm pressão insuficiente para reter os hidrocarbonetos

Figura 6 - Camada de rocha selante com diferentes capilaridades controlando o potencial de retenção (mod. Allen \& Allen 1990).
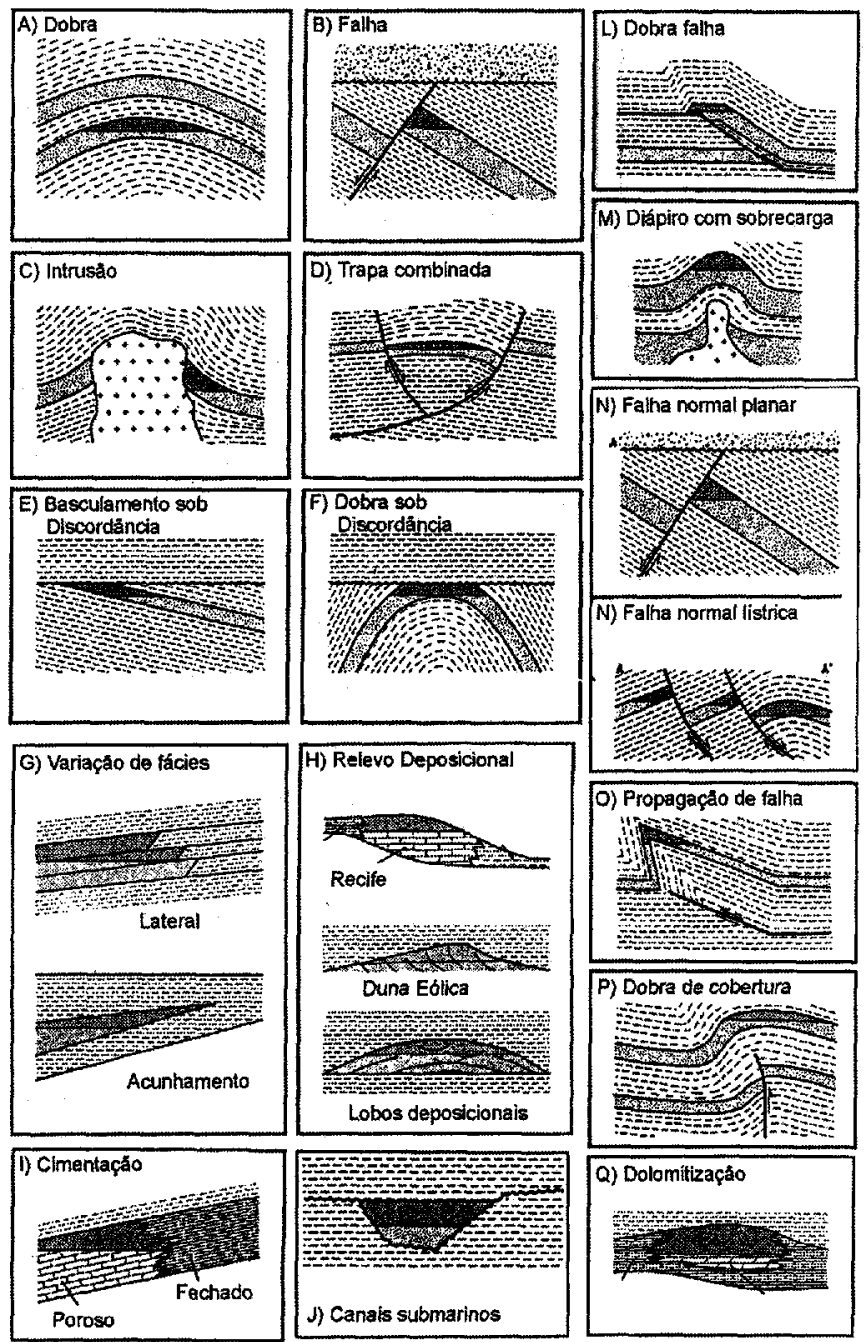

N) Falha normal listrica

Figura 7 - Modelos de trapeamento (mod. Biddle \& Wielchowsky 1994).

$$
P\left(B_{i} \mid A\right)=\frac{P\left(B_{i} \cap A\right)}{P(A)}
$$

com

$$
P\left(A \mid B_{i}\right)=\frac{P\left(B_{i} \cap A\right)}{P\left(B_{i}\right)} \Rightarrow P\left(B_{i} \cap A\right)=P\left(A \mid B_{i}\right) P\left(B_{i}\right)
$$

que resulta em: 


$$
P\left(B_{i} \mid A\right)=\frac{P\left(A \mid B_{i}\right) P\left(B_{i}\right)}{P(A)}
$$

com $i=1, \mathrm{n}$, que é o teorema de Bayes. O teorema de Bayes pode ser lido como "se um evento (prospecto) sempre ocorrer com um dos eventos mutuamente exclusivos $B_{1}, B_{2}, \ldots B_{k}$ (fatores diagnósticos), então as probabilidades condicionais destes eventos também podem ser determinadas, deseje que $A$ seja conhecido (tenha ocorrido)". A exploração de petróleo é inerentemente uma atividade bayesiana.

A probabilidade final de uma nova descoberta $D$ dadas $j=1, n$ variáveis, $\mathrm{P}(\mathrm{DIVj})$, é obtida através do produto das probabilidades de sucesso individuais:

$$
P\left(D \mid V_{j}\right)=\prod_{j=1}^{n} P\left(V_{j} \mid A\right) \times P\left(\bar{V}_{j} \mid \bar{A}\right) .
$$

Neste cálculo, o fator retenção obteve uma probabilidade de sucesso muito boa $(0,78)$, em função de sua ocorrência freqüente em áreas positivas $[\mathrm{P}(\mathrm{V} \mid \mathrm{A})=0,83]$ e sua ausência também constante em áreas negativas $[\mathrm{P}(\mathrm{V} \mid \overline{\mathrm{A}})=0,93]$. Já o fator eficiência, embora estivesse presente em 25 dos $3^{n}$ poços produtores (urna freqüência razoável), também ocorria em grande parte dos poços não produtores (40), situação que configura um valor relativamente alto de suficiência, porém um baixo valor de necessidade, resultando em probabilidade de sucesso regular, de apenas 0,36 . A probabilidade final $P(D \mid V j)$ resultante é baixa, de 0,029 ou $2,9 \%$, o que torna o prospecto pouco compensador, principalmente em função dos valores 0,25 e 0,36 calculados para os fatores alimentação e eficiência.

Hierarquização de Alvos Um problema que surge com a extensão das informações exploratórias para vários alvos é a heterogeneidade na distribuição dos fatores diagnósticos. Uma área alvo pode conter todos os fatores existentes nas áreas de controle, ou então conter apenas uma parte deles. Caso seja utilizado o mesmo procedimento de multiplicação de probabilidades independentes em cada área alvo, aquela que contiver um número menor de variáveis indicativas pode resultar em valores maiores de probabilidades, mesmo que o conjunto de dados seja menos representativo. Por exemplo, sejam consideradas $4^{1}$ áreas na mesma bacia, utilizando o modelo de acumulação do exemplo anterior (Tabela 9). Para a área 4 foi obtido valor de $14,5 \%$ de probabilidade final, enquanto a área 1 teve $2,9 \%$. A simples análise destes números poderia sugerir que a área 4 é melhor do que a 1 , embora seja fácil perceber intuitivamente que o valor encontrado é irreal, já que eram conhecidos apenas 2 fatores diagnósticos na área 4. Logicamente, este resultado resulta de uma análise errônea, pois a inexistência de informação induz a uma chance de sucesso menor. Entretanto, a representatividade dos dados é incluída no cálculo para retirar a tendenciosidade advinda da análise de áreas com conhecimento diferenciado. Dessa forma, a probabilidade de uma nova descoberta deve ser vista como uma "probabilidade da área", com valor único, seja ela na escala de província, regional ou detalhe, tendo como base as variáveis do sistema petrolífero. Uma das modificações apresentadas neste trabalho consiste em considerar diferentes distribuições de variáveis (o modelo considerado será necessariamente o mesmo para toda a área, já que é baseado no mesmo conjunto de dados). Justamente neste ponto do raciocínio surge a importância do post-mortem, porque possibilita ao intérprete retroalimentar o modelo e avaliar se as variáveis do modelo modificado estão presentes ou não nas áreas escolhidas para locação. Em cada locação, têm-se a probabilidade do sistema petrolífero estar correto (baseada nas variáveis regionais) mais a probabilidade do prospecto ser positivo (baseada nas variáveis locais, obviamente calibradas pelas variáveis regionais). A probabilidade final depende por um lado da conceituação do sistema petrolífero e por outro do conhecimento acerca da área a ser testada. Assim, para hierarquizar alvos de pesquisa, a quantidade de fatores diagnósticos presentes (ou representatividade do banco de dados) deve ser também analisada.

A representatividade dos dados em cada célula alvo é definida pela combinação das variáveis indicativas nela presentes, de modo similar aos modelos de sobreposição indexada (index overlay models; Bonham-Carter 1994). Tais modelos são utilizados em sistemas de informação geográficas (SIGs), onde as variáveis são binárias (ou discretas $\mathrm{O}$ e 1 como aqui definido) e cada mapa é multiplicado por um fator de

Tabela 6 - Classificação de trapas (mod. Allen \& Allen J990).

\begin{tabular}{|ll|l|l|}
\hline 1. & Estrutural & Tectônica & $\begin{array}{l}\text { Extensional } \\
\text { Contracional } \\
\text { Estruturas de Cobertura } \\
\text { Halocinese/Argilocinese } \\
\text { Diapírica } \\
\text { Gravitacional }\end{array}$ \\
\hline 2. & Estratigráfica & Deposicional & $\begin{array}{l}\text { Recifes } \\
\text { Acunhamentos Laterais } \\
\text { Canais } \\
\text { Barras } \\
\text { Truncamento } \\
\text { Onlap }\end{array}$ \\
& Discordâncias & Diagenética & \\
\hline 3. & Hidrodinâmica & & \\
\hline 4. & Combinada & & \\
\hline
\end{tabular}

Tabela 7 - Informações utilizadas para a análise de incertezas em

\begin{tabular}{|c|c|c|}
\hline FATOR DIAGNÓSTICO & Tipo de Variável & \begin{tabular}{|c|} 
Critério Diagnóstico \\
\end{tabular} \\
\hline \multicolumn{3}{|l|}{ A. GERADORA } \\
\hline Potencial gcrador (COT, S1+S2, SPD) & Contínua & Cutoff \\
\hline Espessura ou volume de rocha geradora & Contínua & Cutoff \\
\hline Extensão areal c continuidade & Contínua & Cutoff \\
\hline Tipo de querogénio & Discreta & Adequado/nadequado \\
\hline \multicolumn{3}{|l|}{ B. RESER VATÓRIO } \\
\hline Litologia & Discreta & Adequado/nadequado \\
\hline Modelo Deposicional & Discreta & Adequado'Inadequado \\
\hline Continuidade lateral e extensão & Continua & Cutoff \\
\hline Espessura e variabilidade vertical & Contínua & Culoff \\
\hline Capacidade Volumérrica & Contínua & Cutoff \\
\hline Transmissibilidade de Fluidos & Contínua & Cutoff \\
\hline Hetcrogeneidade & Discreta & \begin{tabular}{|l} 
Adequado/Inadequado \\
\end{tabular} \\
\hline \multicolumn{3}{|l|}{ C. ALIMENTAÇĀO } \\
\hline Potencial volumétrico & Conlínua & Cutoff \\
\hline Fluxo térmico & Contínua & Cutoff \\
\hline Mecanismos de migrafẫo e zonas de convergênncia & Discreta & \begin{tabular}{|l} 
Adequado/nadequado \\
\end{tabular} \\
\hline Entropia do sistema (tendência à dispersão) & Discreta & \begin{tabular}{|l} 
Adequado/Inadequado \\
\end{tabular} \\
\hline \multicolumn{3}{|l|}{ D. RETENCĀO } \\
\hline Tipo de trapa (anticlinal, falha, pinch-out, etc) & Discreta & \begin{tabular}{|l} 
Adequado/Inadequado \\
\end{tabular} \\
\hline Qualidade da lrapa (mélodo, confiabilidade) & Discreta & Adequado/nadequado \\
\hline
\end{tabular}
sistemas petroliferos.

Tabela 8 - Exemplo de cálculo das condições de necessidade e suficiência, e probabilidades de sucesso referentes às variáveis. Considera-se um total de 100 poços, dos quais 30 são produtores (A - caso positivo) e 70 são secos (- caso negativo). Fator Geração - Total de 50 ocorrências (tendência dominante de critérios diagnósticos presentes), sendo 30 em prospectos positivos e 20 em negativos. Não ocorre (critério diagnóstico ausente) em 50 dos casos negativos. Fator Reservatório - Total de 30 ocorrências, sendo 20 em prospectos positivos e 10 em negativos. Não ocorre em 10 casos positivos e em 60 negativos. Fator Alimentação - Total de 50 ocorrências, sendo 15 em prospectos positivos e 35 em negativos. Não ocorre em 15 casos positivos e em 35 negativos. Fator Retenção - Total de 30 ocorrências, sendo 25 em prospectos positivos e 5 em negativos. Não ocorre em 5 casos positivos e em 65 negativos. Fator Eficiência - Total de 65 ocorrências, sendo 25 em prospectos positivos e 40 em negativos. Não ocorre em 5 casos positivos e em 30 negativos.

\begin{tabular}{|l|l|l|c|c|c|c|c|c|c|}
\hline Fator & $V$ & $\bar{V}$ & $V \cap A$ & $\bar{V} \cap A$ & $V \cap \bar{A}$ & $\bar{V} \cap \bar{A}$ & $P(\bar{V} \mid \bar{A})$ & $P(V \mid A)$ & $P S=P(\bar{V} \mid \bar{A}) \times P(V \mid A)$ \\
\hline Geração & 50 & 50 & 30 & 0 & 20 & 50 & 0,71 & 1,00 & 0,71 \\
\hline Reservatório & 30 & 70 & 20 & 10 & 10 & 60 & 0,86 & 0,67 & 0,58 \\
\hline Alimentação & 50 & 50 & 15 & 15 & 35 & 35 & 0,50 & 0,50 & 0,25 \\
\hline Retenção & 30 & 70 & 25 & 5 & 5 & 65 & 0,93 & 0,83 & 0,78 \\
\hline Eficiência & 65 & 35 & 25 & 5 & 40 & 30 & 0,43 & 0,83 & 0,36 \\
\hline
\end{tabular}


ponderação. Os mapas ponderados são somados e normalizados pela soma dos ponderadores, da seguinte forma:<smiles>CC(C(C)(C)C)C(C)(C)C</smiles>

(Bonham-Carter 1994)

onde $W j$ são os pesos dos mapas i ( $\mathrm{i}=1, \mathrm{n})$ e a classe $\left(M A P A_{i}\right)$ é 1 ou $\mathrm{O}$ para a condição binaria presente ou ausente, respectivamente. O resultado é um mapa com escores entre O (extremamente desfavorável) e 1 (altamente favorável), onde estão discriminadas as melhores áreas.

Desde que as células sejam pequenas o bastante para existir no máximo 1 acumulação por célula, pode-se dizer que haverá $n$ células de controle contendo acumulações conhecidas. A chance de ocorrer uma descoberta pode ser obtida através da extensão das condições de necessidade e suficiência calibradas nas células de controle para todas as células que contenham as variáveis consideradas. A correlação de dados espaciais é desenvolvida por meio da integração dos vários níveis de informação. Os mapas compostos contêm um grid de células constantes em tamanho, forma e orientação (pixels), distribuídas horizontalmente em níveis, onde as variáveis indicativas são armazenadas em planos individuais. Nesse modelo, a integração é efetuada pela combinação dos atributos que estão na mesma posição espacial , em diferentes camadas superpostas (Fig. 8).

Para a análise de incertezas, o mesmo procedimento pode ser aplicado para cada célula alvo. A representatividade (r) é calculada pela relação entre o somatório das $\mathrm{i}=1, \mathrm{n}$ probabilidades de sucesso obtidas na célula alvo e o somatório das $\mathrm{j}=1, \mathrm{n}$ probabilidades de sucesso utilizadas para calibração, da seguinte forma:

$$
r=\frac{\sum_{i=1}^{n} P S}{\sum_{j=1}^{n} P S}
$$

onde PS é a probabilidade de sucesso para a célula

A probabilidade final do modelo, ou probabilidade $P F_{m o d}=P\left(D \mid \mathrm{V}_{\mathrm{i}}\right.$ é representada pela condição ideal (presença de todas as $\mathrm{j}=1, \mathrm{n}$ variáveis do modelo de sistema petrolífero considerado). Para obtenção da probabilidade de uma nova descoberta na célula alvo $P\left(D \mid \mathrm{V}_{\mathrm{i}}\right.$ com $\mathrm{i}=1$, $\mathrm{n}$ variáveis indicativas (Tabela 10$)$, a $P F_{\text {mod }}$ deve ser multiplicada pelo valor $\mathrm{r}$ (considerando as $\mathrm{i}=1, \mathrm{n}$ variáveis).

ESTUDO DE CASO Para demonstrar o método discutido, procedeu-se a avaliação de uma área fíctícia, cuja características exploratórias reproduzem um estilo de bacia rifte evoluindo para margem

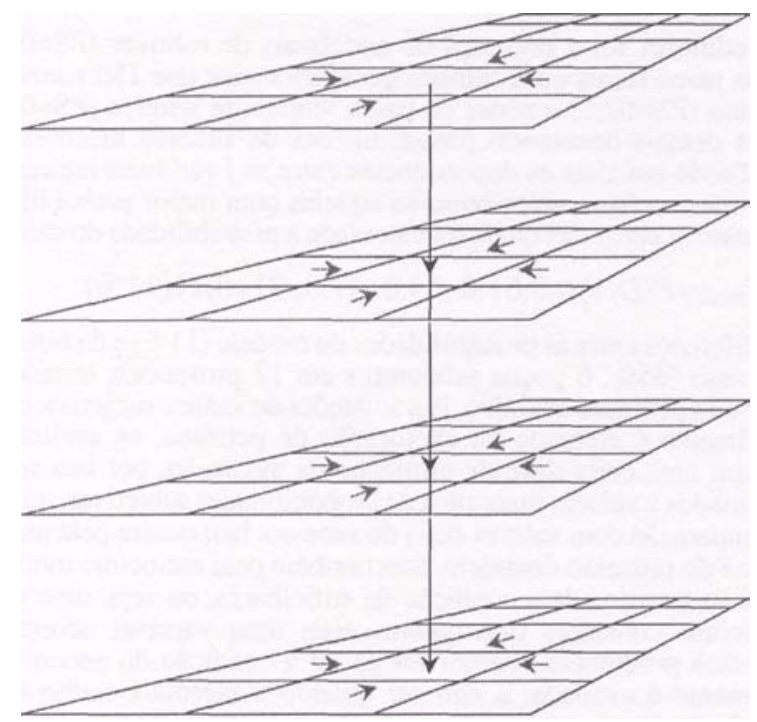

Figura 8 - Modelo de mapa composto representando a correlação espacial, onde os valores para cada variável indicativa são combinados na mesma camada (adaptado de Shepherd 1991). passiva. O modelo de acumulação (Fig. 9) compreende baixos de falhas lístricas, com falhas sintéticas, antitéticas e rollovers associados a uma tectônica halocinética. Considera-se que a migração foi principalmente vertical na área.

O fator geração foi avaliado a partir do índice de potencial gerador - SPI (Fig. 10a) e isópacas da camada geradora (Fig. 1 Ob). A camada geradora apresenta maior espessura na porção noroeste, tendo sido incluída na seção rifte, o que sugere áreas subsidentes mais próximas à charneira da bacia. Já os dados de SPI indicam um condicionamento a um trend NE, um pouco deslocado para sudeste dos depocentros definidos para a seção geradora. A relação espacial entre o topo da camada geradora e as isolinhas de maturação (Ro) foi considerada para a interpretação da área de drenagem (Fig. 10c). A convergência das direções de fluxo foi no sentido de altos desta superfície, principalmente a partir de regiões de maior valor de Ro, induzido pelo gradiente geotérmico regional (Fig. 10d), e também ascendente, contra o mergulho regional da bacia. Como dutos potenciais para a migração a partir da seção geradora foram consideradas as falhas que afetam seção rifte (Fig. lia).

O mapa de fácies sedimentares foi construído inferindo-se um nível reservatório pertencente à seção pós-rifte $(\mathrm{Fig}$. $1 \mathrm{Ib})$. O padrão observado mostra o aporte de uma região alta a noroeste, onde ocorre uma plataforma essencialmente argilosa, e um talude controlando a de; posição de fácies gravitacionais mais profundas na porção sudeste. É possível observar que os principais canais de alimentação dos sistemas profundos apresentam um suprimento por sistemas fluvio-deltaicos na porção centro-noroeste em direção a uma bacia a sudeste. Para o sistema petrolífero considerado, as fácies reservatório estão situadas nas porções canalizadas e nas frações mais arenosas do leque e cunha de mar baixo, que refletem a sedimentação em calhas de captação de areias com direção preferencial noroeste-sudeste. A direção destas calhas, oblíquas ao arcabouço estrutural da bacia, sugerem que as falhas observadas no embasamento não foram feições ativas durante a deposição da rocha reservatório. Na elaboração do modelo fíctício

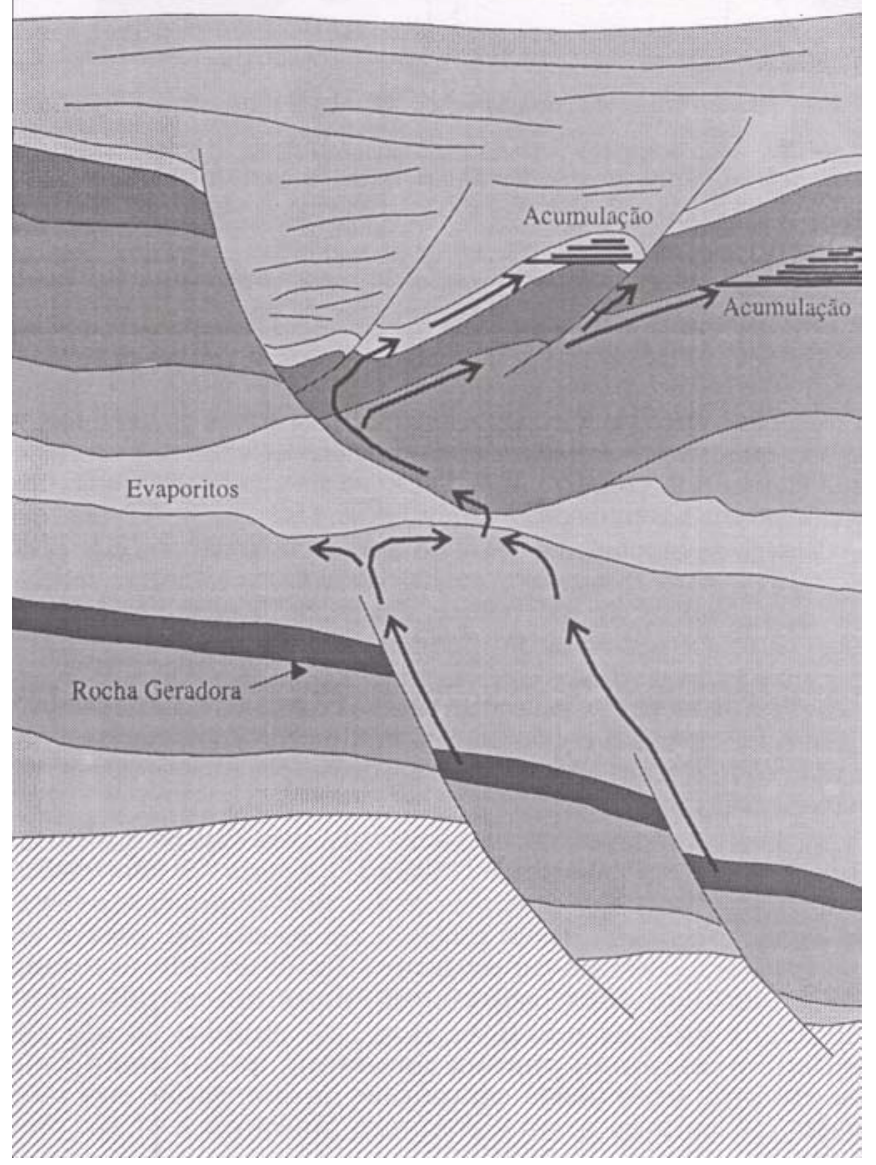

Figura 9 - Modelo de acumulação para a área fictícia, com alimentação a partir da seção rifte e acumulação na seção pós-rifte, em baixos de falhas lístricas. 

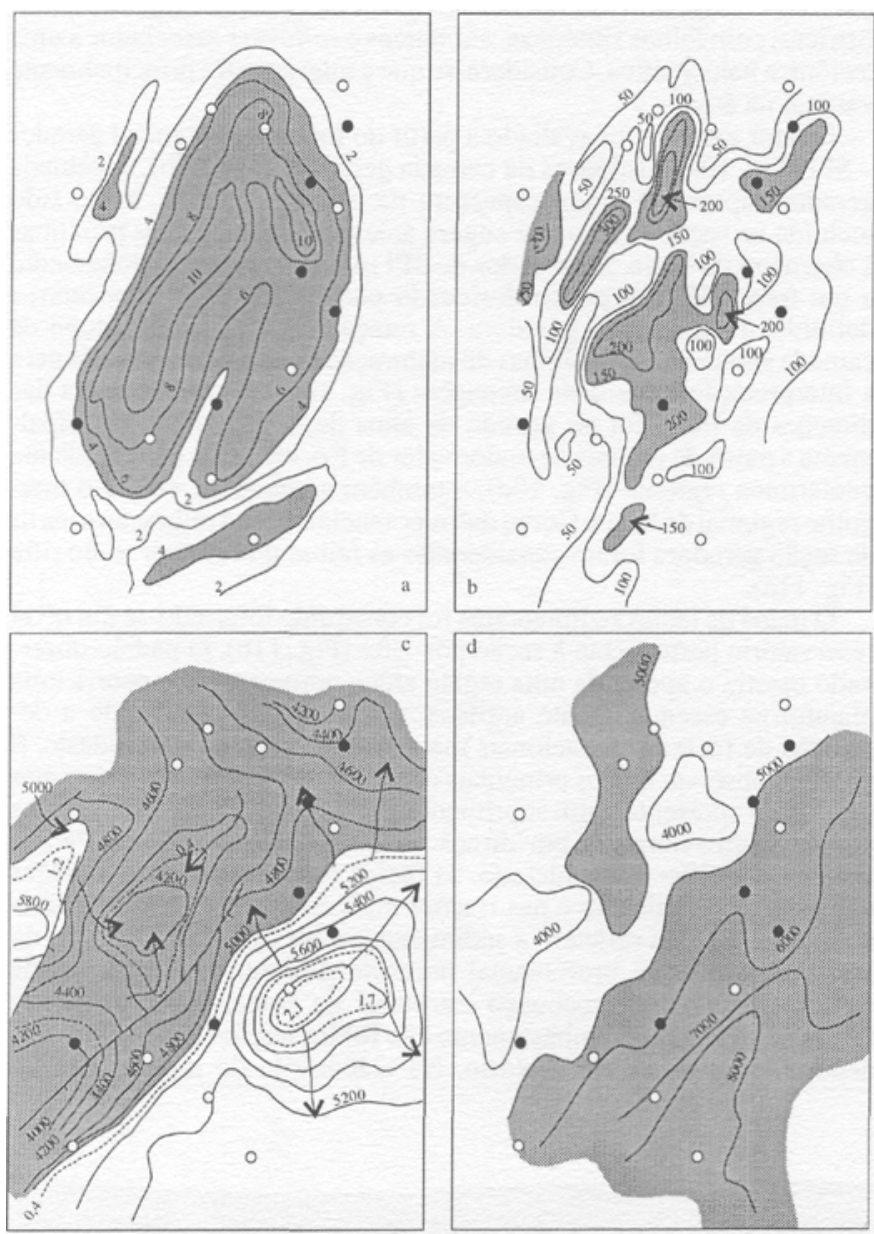

Figura 10 - a) Mapa de isovalores de SPI ( $k^{\wedge} H c /$ ton rocha); b) Mapa de isópacas da rocha geradora (metros); c) Área de drenagem (linhas contínuas - contorno estrutural da camada geradora em metros; linhas pontilhadas - isovalores de reflectância da vitrinita); d) Mapa de isoprofundidade da isoterma de $120^{\circ} \mathrm{C}$ (metros). Os círculos representam os poços (produtores - sólidos; secos - vazados) e as cruzes os prospectos não testados. Áreas em tons de cinza representam as variáveis indicativas.

considerou-se ainda um mapa de amplitudes sísmicas do nível reservatório, que estão controladas pela maior compactação a sudeste e pela predominância de racies argilosas de talude em uma faixa estreita com amplitude alta e continuidade variável (Fig. 11c).

O mapa de estruturas ao nível do topo do reservatório (Fig. $11 \mathrm{~d}$ ) mostra as áreas de fechamento, evidenciando várias estruturas anticlinais condicionadas aos movimentos das falhas lístricas e colapso do bloco baixo. Do mesmo modo, observam-se diápiros de sal, que estão concentrados na porção sudeste. As principais estruturas para retenção encontram-se na porção central da bacia, segundo uma faixa paralela à charneira, restrita à região onde o espalhamento gravitacional foi mais intenso. A rocha selante ocorre em quase toda a bacia, exceto nas porções mais rasas a noroeste.

As diversas variáveis foram discretizadas com base no modelo de sistema petrolífero considerado (Tabela 11), a partir das informações "encontradas" nos poços existentes, com as quais construiu-se o banco de dados. O trabalho inicial consistiu em montar um arquivo de coordenadas $\mathrm{x}, \mathrm{y}$ definido por células de 100x100 unidades (o modelo não apresenta uma correspondência com valores reais em quilômetros; Fig. 12a) e variáveis indicativas $\mathrm{z}_{1}, Z_{2},--, Z_{\mathrm{n}}$, presentes ou não nas células. Em cada um dos pontos de amostragem, fez-se a leitura direta das variáveis, sendo obtido um conjunto de informações para calibração (10 variáveis $z_{\mathrm{n}}$ em 6 prospectos produtores e 11 não produtores).

As probabilidades parciais de sucesso induzidas para cada variável (Tabela 12) demonstram a ordem de importância das mesmas para a predição de novas descobertas. A variável melhor associada aos cam-
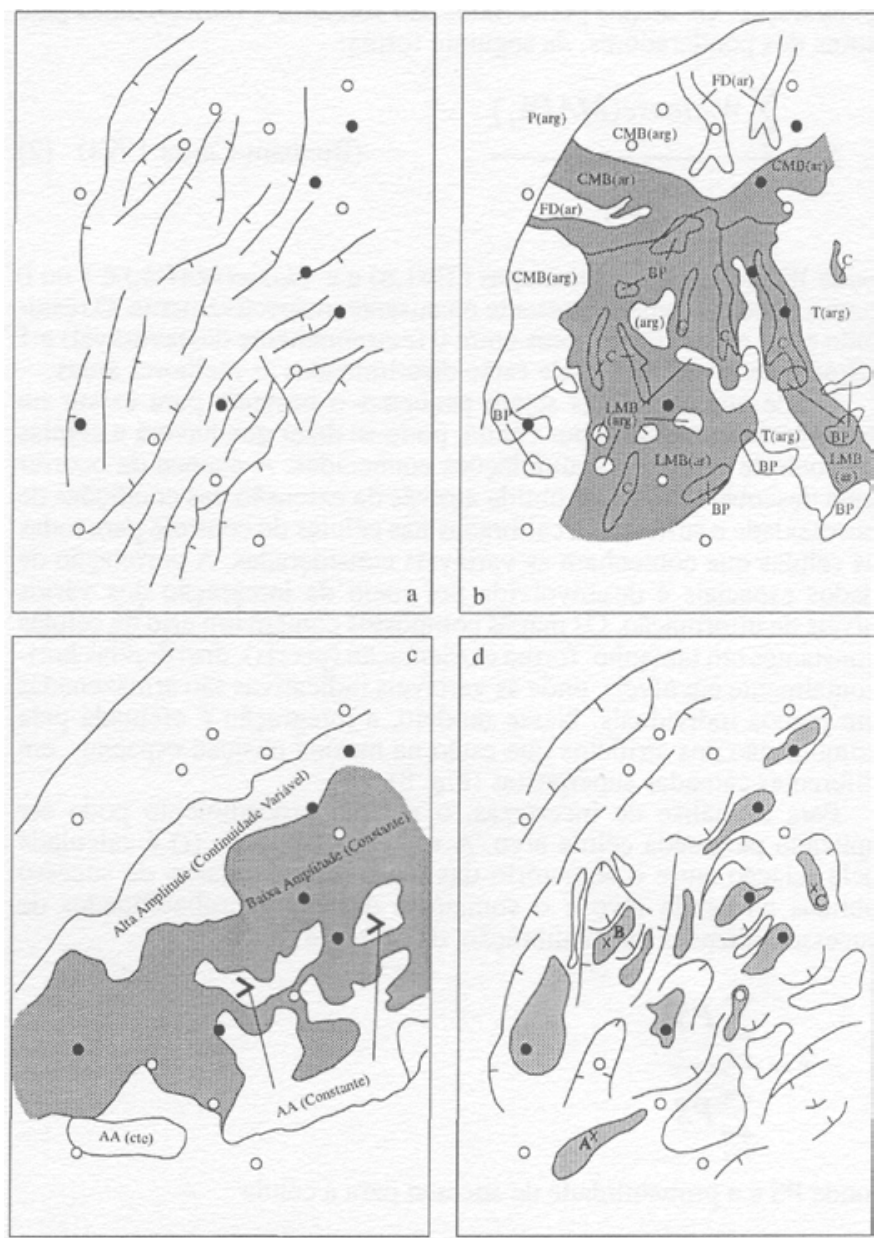

Figura 11 - a) Mapa de falhas mapeadas na parte superior da seção rifle; b) Mapa de ambientes e fades deposicionais ( $P$ - talude; $C M B$ - cunha de mar baixo; $L M B$ - leque de mar baixo; $F D$-frente deltaica; $T$ - talude; arg - argilitos; ar - arenitos); c) Mapa de amplitudes sísmicas; d) Mapa estrutural, contendo falhas da seção pós-rifte, anticlinais de rollover (polígonos preenchidos), domos e diápiros (polígonos vazios). Os círculos representam os poços (produtores sólidos; secos - vazados) e as cruzes os prospectos não testados. Áreas em tons de cinza representam as variáveis indicativas.

pos produtores foi a presença de anticlinais de rollover $(\mathrm{PS}=0,91)$, seguida pelos locais com camada geradora maior que 150 metros de espessura $(\mathrm{PS}=0,61)$ e zonas de baixa amplitude sísmica $(\mathrm{PS}=0,53)$, com as demais denotando probabilidades de sucesso menores que $50 \%$. Tendo em vista as dependências entre as $\mathrm{j}$ variáveis indicativas de um mesmo fator, selecionou-se aquelas com maior probabilidade de sucesso, a partir das quais foi calculada a probabilidade do modelo:

$$
P F_{\text {mod }}=P\left(D \mid V_{j}\right)=0,61.0,53.0,37.0,91=0,11(11 \%)
$$

A diferença entre as probabilidades do modelo (11\%) e do histórico de sucesso $(35 \%, 6$ poços produtores em 17 prospectos testados) é inerente ao processo analítico. Em situações de análise subjetiva, como normalmente é efetuado na exploração de petróleo, os avaliadores embutem uma certa dose de otimismo na avaliação, por isto somos acostumados a valores mais altos de probabilidades subjetivas, quando em comparação com valores reais de sucesso. Isto ocorre pela própria natureza do processo decisório, mas também pelo raciocínio intuitivo, onde é superestimada a condição de suficiência, ou seja, uma visão tendenciosa considera que quanto mais uma variável ocorre em prospectos produtores, melhor ela é). Já a condição de necessidade dificilmente é avaliada, a não ser quando a mesma é muito baixa tornando inviável o prospecto, por exemplo, inexistência de rocha geradora ou selo, etc. Dessa forma, é razoável assumir que a utilização de um banco de dados incompleto leva a uma diminuição da chance de sucesso. Por melhor que seja o modelo, ele sempre é uma representação incompleta da realidade. 
Tabela 9 - Comparação entre 4 prospectos, com base no mesmo conjunto de variáveis da tabela VIII.

\begin{tabular}{|lcccc|}
\hline Geraçăo & Área 1 & Área 2 & Área 3 & Area 4 \\
Reservalório & 0,71 & 0,71 & 0,71 & Inexistente \\
Alimentação & 0,58 & 0,58 & Inexistente & 0,58 \\
Retençăo & 0,25 & 0,25 & 0,25 & 0,25 \\
Eficiência & 0,78 & Incxistente & 0,78 & Inexistente \\
$P\left(D \mid V_{j}\right)$ & 0,36 & 0,36 & Inexistente & Inexistente \\
\hline
\end{tabular}

Tabela 10 - Probabilidades calculadas para o exemplo anterior.

\begin{tabular}{|l|c|c|c|c|}
\hline & Prospecto A & Prospecto B & Prospecto C & Prospecto D \\
\hline Rocha Geradora & 0,71 & 0,71 & 0,71 & Inexistente \\
\hline Rocha Reservatório & 0,58 & 0,58 & Inexistente & 0,58 \\
\hline Alimentaçăo & 0,25 & 0,25 & 0,25 & 0,25 \\
\hline Retenção & 0,78 & Inexistente & 0,78 & Inexistente \\
\hline Eficiência & 0,36 & 0,36 & Inexistente & Inexistente \\
\hline$\sum_{i=1}^{n} P S$ & 2,68 & 1,9 & 1,74 & 0,83 \\
\hline$\sum_{j=1}^{n} P S$ & & & & \\
\hline$r$ & 2,68 & 2,68 & 2,68 & 2,68 \\
\hline$P\left(D \mid V_{j}\right)=P F_{\mathrm{m}}$ & & & & \\
\hline$P\left(D \mid V_{i}\right)=P F_{\mathrm{a}} \cdot r$ & 0,029 & 0,021 & 0,019 & 0,009 \\
\hline
\end{tabular}

Os prospectos A, B e C (Fig. 12a,b) foram hierarquizados utilizando-se as variáveis presentes. Os valores resultantes (Tabela 13) indicam que o prospecto $\mathrm{B}$ é o melhor prospecto, enquanto os prospectos A e C apresentam valores menos favoráveis. Com o cálculo de $P(V \mid D i)$ para todas as células da área, obteve-se a distribuicão regional de probabilidades de sucesso (Fig. 12b). O mapa de probabilidades de ocorrência de novas acumulações em toda a área avaliada mostra claramente que há dois locais altamente favoráveis (indicados pelas letras Y e Z na figura $12 \mathrm{a}, \mathrm{b}$ ), anteriormente não considerados como alvo de pesquisa. Este resultado demonstra que a quantificação da importância dos fatores diagnósticos tanto em poços produtores como em poços secos é fundamental, tendo sido devidamente analisadas suas probabilidades de sucesso com base nas condições de necessidade e suficiência.

CONCLUSÕES A calibração do modelo probabilistic tanto em áreas não produtoras como produtoras, com o intuito de definir a necessidade e suficiência de variáveis exploratórias, mostrou-se adequada à predição de novas descobertas em regiões ainda não testadas. O modelo apresentado, envolvendo a análise de probabilidades condicionais e a modelagem de sistemas petrolíferos representa um processo contínuo de atualizacão do conhecimento com base em bancos de dados orientados, auxiliando na avaliação das chances de sucesso de prospectos ou de áreas alvo. Um dos aspectos mais importantes foi estabelecer um procedimento padrão que incorpora a análise de fatores diagnósticos em todos os prospectos testados. Ou seja, considerou-se fundamental conhecer o comportamento das variáveis tanto nos pocos produtores como nos secos. Para uma variável ser considerada muito importante para a predição, é preciso que a mesma tenha um grau alto de suficiência (ocorra com freqüência em áreas positivas) e também um grau alto de necessidade (não ocorra em áreas negativas). Normalmente esta segunda dimensão da análise de prospectos, envolvendo poços secos, não é considerada para definir as probabilidades de sucesso. No presente trabalho, demonstrou-se como as condições de necessidade e suficiência podem ser facilmente calculadas com o auxílio dos métodos de análise probabilística, tendo como condicionantes as áreas de controle representadas por todos os prospectos testados. Da mesma forma, foi estabelecida uma metodologia para estimar a distribuição areai de probabilidades, desde que estejam disponíveis mapas de variáveis indicativas que representam os elementos essenciais de sistemas petrolíferos. Embora a avaliação subjetiva
Tabela 11 - Variáveis e cutoffs utilizados para avaliação da área ficticia.

\begin{tabular}{|c|c|}
\hline Fator Diagnóstico e Variáveis & Critério \\
\hline \multicolumn{2}{|l|}{ A. GERADORA } \\
\hline Potencial gerador (SPI) & Cutoff (>4kgHC/ton) \\
\hline Isópacas da rocha geradora & Cutoff $(>150 \mathrm{~m})$ \\
\hline \multicolumn{2}{|l|}{ B. RESERVATORIO } \\
\hline Mapa de fácies deposicionais & Associaçőes arenosas (CMB,LMB), Canais \\
\hline Mapa de amplitude & Zonas de baixa amplitude \\
\hline \multicolumn{2}{|l|}{ C. ALIMENTAÇÃO } \\
\hline Área de drenagem e zonas de convergência & Cutoff $(<5000 \mathrm{~m})$ \\
\hline Fluxo térmico-Isotema de $120^{\circ} \mathrm{C}$ & Cutoff $(>5000 \mathrm{~m})$ \\
\hline Falhas na sç̧̃o riftc & \begin{tabular}{|l|l|} 
Presença \\
\end{tabular} \\
\hline \multicolumn{2}{|l|}{ D. RETENCCAOO } \\
\hline Anticlinais de Rollover & Presença \\
\hline Isópacas da camada selante & Cutoff $(>30 \mathrm{~m})$ \\
\hline \multicolumn{2}{|l|}{ E. EFICIÉNCIA } \\
\hline Timing & \begin{tabular}{|l|} 
Considerado favorável em loda a área \\
\end{tabular} \\
\hline
\end{tabular}

Tabeja 12 - Cálculo dos graus de suficiência -P(V\A) - e necessidade - $P(V \mid \bar{A})$ - e das probabilidades de sucesso induzidas pelas variáveis presentes na área fictícia.

\begin{tabular}{|c|c|c|c|c|c|c|}
\hline Yariável Indicativa & $\bar{V} \cap A$ & $P(V \mid A)$ & $\bar{V} \cap \bar{A}$ & $P \bar{V} \mid \bar{A}$ & $P S$ & $\begin{array}{l}P S \text { do Fator } \\
\text { Diagnóstico }\end{array}$ \\
\hline SPI & 5 & 0,83 & 3 & 0,27 & 0,22 & \\
\hline 1soppacas Gcradora & 4 & 0,67 & 10 & 0,91 & \begin{tabular}{|l|}
0,61 \\
\end{tabular} & $\rightarrow 0,61$ \\
\hline Fácies Rescrvatório & 4 & 0,67 & 8 & 0,73 & 0,49 & \\
\hline Amplitude Sísmica & 5 & 0,83 & 7 & 0,64 & \begin{tabular}{|l|}
0,53 \\
\end{tabular} & $\rightarrow 0,53$ \\
\hline Área de Drenagem & 5 & 0,83 & 5 & 0,45 & 0.37 & $\rightarrow 0,37$ \\
\hline Isotermas $120^{\circ} \mathrm{C}$ & 4 & 0,67 & 4 & 0,36 & 0,24 & \\
\hline 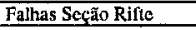 & 2 & 0,33 & 6 & 0,54 & 0,18 & \\
\hline Anticlinais de Rollover & 6 & 1,00 & 10 & 0,91 & 0,91 & $\rightarrow 0,91$ \\
\hline Sclo & 6 & 1,00 & 5 & 0.45 & $0,4.5$ & \\
\hline
\end{tabular}

Tabela 13 - Resultados para os prospectos A, Be C (para localização, ver figura 19).

\begin{tabular}{|l|c|c|c|}
\hline Prospecto & A & B & C \\
\hline Coord X & 500 & 600 & 1400 \\
\hline Coord Y & 400 & 1200 & 1400 \\
\hline SPI & Inexistente & 0,22 & Inexistente \\
\hline Isópacas da Gcradora & Inexistente & Inexistente & Inexistente \\
\hline F́́cies Reservatorio & 0,49 & 0,49 & Inexistente \\
\hline Amplitude & Inexistente & 0,53 & 0,53 \\
\hline Drcnagem & Inexistentc & 0,37 & Inexistente \\
\hline Isolcrma & 0,24 & 0,24 & 0,24 \\
\hline Falha Riftc & 0,18 & 0,18 & Inexistente \\
\hline Rollover & 0,91 & 0,91 & 0,91 \\
\hline Sclo & 0,45 & 0,45 & 0,45 \\
\hline$\sum_{i=1}^{n} P S$ & 2,27 & 3,39 & 2,13 \\
\hline$\sum_{j=1}^{n} P S$ & & & \\
\hline$r$ & 4,00 & 4,00 & 4,00 \\
\hline$P\left(D \mid V_{j}\right)=P F_{\text {maxima }}$ & & & \\
\hline$P\left(D \mid V_{i}\right)=P F_{\text {maxima }} \cdot r$ & $0,063(6,3 \%)$ & $0,094(9,4 \%)$ & $0,0586(5,9 \%)$ \\
\hline
\end{tabular}

dos parâmetros de entrada permaneça embutida no método proposto, o julgamento intuitivo é reduzido no modelo. Isto ocorre em tal nível que é possível a hierarquização de vários prospectos em uma mesma bacia, ou em áreas análogas, desde que tenha sido feito o armazenamento adequado de variáveis indicativas em um banco de dados georreferenciado orientado pela análise de sistemas petrolíferos. O teste em uma área fictícia, construída com base em modelos reais de bacias rifte e margem passiva prolíficas, mostrou uma correspondência satisfatória entre as predições e os resultados de post-mortem, cujo banco de dados armazenado foi utilizado como controle para calibração. Os resultados incluem a hierarquização de prospectos e mapas de probabilidades de sucesso de novas descobertas.

Agradecimentos Ao apoio financeiro da FINEP/PADCT (projeto n. 65950801-02) e ao Dr. João Carlos Biondi e Ms. Paulo César Arthur pela troca de idéias sobre o tema e revisão do texto. 

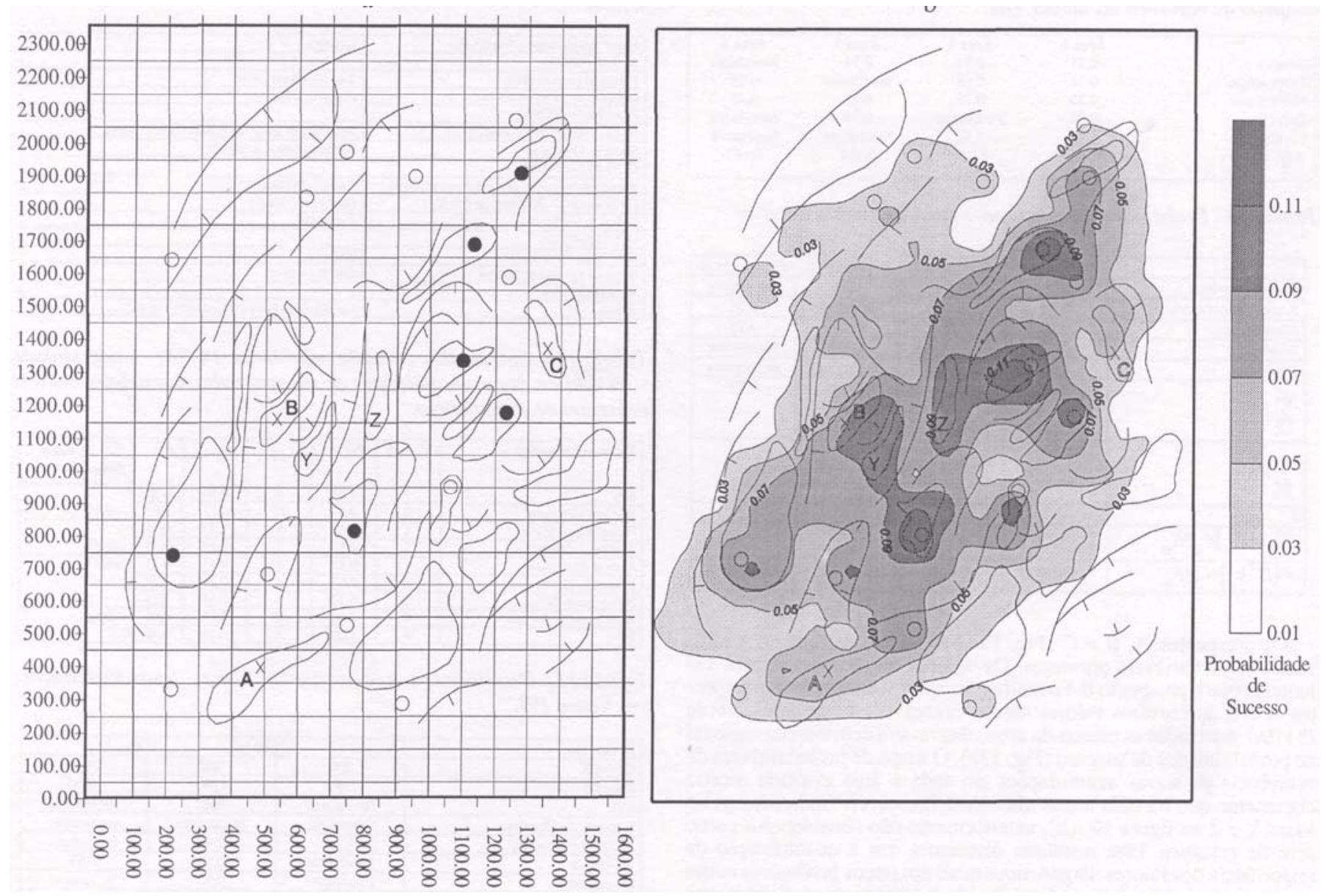

Figura 12 - a) Compartimentação da área em células de 100 por 100 metros, utilizadas para avaliação de probabilidades de sucesso; b) Mapa de probabilidades de sucesso.

\section{Referências}

Allen, P.A. \& Allen, J.R. 1990. Basin analysis - principles and applications. London: Blackwell, $451 \mathrm{p}$.

Biddle, K.T. \& Wielchowsky, C.C. 1994. Hydrocarbon Traps. AAPG Memoir n.60, p. 219-236.

Bonham-Carter, G.F. 1994. Geographic Information Systems for Geoscientists - Modelling with GIS. Computer Methods in the Geosciences, Volume 13. 1st edition, Canada, Pergamon Press, 398p.

Cross, T.A.; Baker, M.R.; Chapin, M.A.; Clark, M.S.; Gardner, M.H.; Hanson, M.S ; Lessenger, M.A., Little, L.D.; McDonough.K.J.; Sonnenfeld, M.D.; Valasek, D.W.; Williams, M.R.; Witter, D.N. 1993. Applications of high-resolution sequence stratigraphy to reservoir analysis. In: Eschard,R.; Doligez,B. eds. Subsurface reservoir characterization from outcrop observations. Instituí Français du Petrole, Editions Technip, Paris, p.1 1-33.

Demaison, G. \& Huizinga, B.J. 1991. Genetic classification of petroleum systems. AAPG Bulletin, v.75, n.10, p.1626-1643.

Demaison, G. \& Huizinga, B.J. 1994. Genetic classification of petroleum systems using three factors: charge, migration and entrapment. AAPG Memoir n.60, p. 73-89.

Downey, M.W. 1994. Hydrocarbon Seal Rocks. AAPG Memoir n.60, p. 159-164.

Hugget, R.J. 1985. Earth surface systems. Berlin: Springer-Verlag, 270 p.

Jordan, C.F.,Jr \& Wilson, J.L. 1994. Carbonate Reservoir Rocks. AAPG Memoir n.60, p. 141-158.

Kosko, B. 1992. Neural networks and fuzzy systems - a dynamical systems approach to machine intelligence. London: Prentice-Hall, $452 \mathrm{p}$.

Magoon, L.B. \&. Dow, W.G. 1994. The petroleum system. AAPG Memoir n.60, p. 3-24.

Miall, A.D. 1997. The Geology of Stratigraphic Sequences. Springer-Verlag, 433 p.

Morse, D.G. 1994. Siliciclastic Reservoir Rocks. AAPG Memoir n.60, p. 121-140.

Otis, R.M. \& Schneidermann, N. 1997. A process for evaluating exploration prospects. AAPG Bulletin, 81(7):1087-1109.
Peters, K.E. \& Cassa, M.R. 1994. Applied Source Rock Geochemistry. AAPG Memoir n.60, p. $93-120$

Rose, P.R. 1993. Chance of success and its use in petroleum exploration. In: Steinmetz,R. ed., The business of petroleum exploration. AAPG Treatise of Petroleum Geology, p.71-86.

Sheperd, I.D.H. 1991. Information Integration and GIS. In: Maguire.D.J.; Goodchild,M.F.; Rhind,D.W. Geographical Information Systems: Principles and Applications. New York: Longman, p.337-360.

Sluijk, D. \& Nederlof, M.H. 1984. Worldwide geological experience as a systematic basis for prospect appraisal. AAPG Memoir n.35, p. 15-26.

Ungerer, P.; Burrus, J.; Doligez, B.; Chénet, P.Y.; Bessis, F. 1990. Basin evaluation by integrated two-dimensional modeling of heat transfer, fluid flow, hydrocarbon generation, end migration. AAPG Bulletin, 74(3):309-335.

Watson, HJ. \& Sprague Jr, R.H. 1991. Os Componentes de uma Arquitetura para DSS. In: Sprague Jr, R.H.; Watson, J.H., eds., Sistema de apoio à decisão. São Paulo: Campus, p. 127-140.

Weber, K.J. \& Mandi, G. 1978. The role of faults in hydrocarbon migration and trapping in Nigerian growth fault structures. $10^{\text {th }}$ Annual Offshore Technology Conference, Houston, Texas. P.2643-2653.

White, D.A. 1980. Assessing oil and gas plays in facies-cycle wedges. AAPG Bulletin, 64(8): $1158-1178$

Manuscrito A-1040 Recebido em 20 de outubro de 1998 Revisão dos autores em 10 de janeiro de 1999 Revisão aceita em 15 de janeiro de 1999 